\title{
Fermentación de los fructanos del Agave tequilana Weber Azul por Zymomonas mobilis y Saccharomyces cerevisiae en la producción de bioetanol
}

José L. Montañez ${ }^{(1)}$, Juan C. Victoria ${ }^{(1)}$, Rebeca Flores $^{(1)}$ y María Á. Vivar ${ }^{(2)}$

(1) Centro Interdisciplinario de Investigación para el Desarrollo Integral Regional, Justo Sierra 28, C.P. 59510, Jiquilpan, Mich.-México. (e-mail: montasoto@yahoo.com.mx).

(2) Instituto Tecnológico de Tuxtepec, Av. Dr. Víctor Bravo Ahuja S/N. Col. 5 de Mayo, Tuxtepec, C.P. 68350, Oaxaca-México

Recibido Feb. 24, 2011; Aceptado Abr. 27, 2011; Versión Final recibida May. 09, 2011

\begin{abstract}
Resumen
Fructanos contenidos en las bases de las hojas del agave fueron extraídos y utilizados como fuente de carbono a varias concentraciones para la producción de bioetanol. Se usaron dos microorganismos etanolgénicos: la levadura Saccharomyces cerevisiae CDBB-L-331 y la bacteria Zymomona mobilis CDBB-B-603. Las hojas del agave tequilero (Agave tequilana Weber Azul) constituyen los residuos agrícolas del cultivo y a pesar de su alto contenido de azúcares reductores totales (ART) y a los grandes volúmenes que anualmente se generan, actualmente no se utilizan. Los resultados muestran que la bacteria Zymomona mobilis es capaz de crecer a mayores concentraciones de ART, produce mayor cantidad de etanol y tolera mayores concentraciones del mismo. El rendimiento en la producción de etanol, la eficiencia de conversión y la productividad volumétrica también fueron mayores cuando la fermentación se llevó a cabo con Zymomona mobilis a una concentración de $20 \%$ de ART.
\end{abstract}

Palabras clave: agave, fructanos, bioetanol, tequila, fermentación

\section{Fermentation of Agave tequilana Weber Azul fructans by Zymomonas mobilis and Sacchamomyces cerevisiae in the production of bioethanol}

\begin{abstract}
Fructans contained in the base of agave leaves were extracted, hydrolyzed and used as carbon source at several concentrations for the production of bioethanol through two different ethanolgenic microorganisms: the yeast Saccharomyces cerevisiae CDBB-L-331 and the bacterium Zymomonas mobilis CDBB-B-603. The leaves of agave tequilana (Agave tequilana Weber Azul) constitute the agricultural crop residues and despite its high content of total reducing sugars (TRS) and the large volumes generated each year, they are not currently used. The results show that Zymomonas mobilis is able to grow to higher levels of TRS produces more ethanol and tolerate higher concentrations of it. The yield in ethanol production, conversion efficiency and volumetric productivity were also higher when fermentation was carried out with Zymomonas mobilis at a concentration of $20 \%$ of TRS.
\end{abstract}

Keywords: agave, fructans, bioethanol, tequila, fermentation 


\section{INTRODUCCION}

La disminución de las reservas mundiales de petróleo ha derivado en un constante incremento en el precio de este combustible fósil y ha generado una creciente preocupación por la seguridad energética y el cambio climático mundial, lo que ha motivado a que científicos de todo el mundo se den a la búsqueda de fuentes alternas de energía renovables, entre las que destaca el uso de la biomasa agrícola para la producción de biocombustibles, actividad que ha sido catalogada como la industria del futuro (Mathews, 2007). Entre los biocombustibles más desarrollados se encuentran el bioetanol y el biodiesel; el bioetanol se obtiene a partir de materias primas ricas en carbohidratos entre las que destacan el maíz, sorgo, caña de azúcar y remolacha azucarera principalmente, mientras que el biodiesel se elabora a partir de materias primas ricas en aceites vegetales como la palma aceitera, canola, soya y algodón (Avinash, 2007). Las tecnologías para la producción de bioetanol vía caña de azúcar y maíz son las más conocidas y maduras. Actualmente Brasil y Estados Unidos son los principales países productores de bioetanol en el mundo; el primero lo obtiene a partir de la caña de azúcar mientras que el segundo a partir del almidón de maíz (Wheals et al., 1999; Torney et al., 2007).

Debido a que la mayoría de los cultivos que se utilizan o se proponen para la producción de biocombustibles también son empleados como, o para la elaboración de alimentos y piensos, esta diversidad de aplicaciones ocasiona una competencia entre los distintos usuarios de dichos cultivos agrícolas, lo que inminentemente tendrá repercusiones directas en la seguridad alimentaria a través de sus efectos en los precios de los productos básicos. Una alternativa viable para la producción de biocombustibles sin afectar la seguridad alimentaria, consiste en utilizar como fuente de carbohidratos fermentables, aquellas materias primas que conforman los residuos agrícolas de los cultivos, pastos, aserrín, virutas de madera, así como residuos sólidos de los animales y los desechos industriales (Prasad et al., 2007).

Dado que la biomasa lignocelulósica constituye la materia orgánica más abundante en el planeta, su utilización para la producción de bioetanol sería la mejor alternativa posible, desafortunadamente esta tecnología aún está en desarrollo (Sánchez y Cardona 2008). Recientemente se ha propuesto el uso de plantas que producen y acumulan fructanos como fuentes más viables para la producción industrial de biocombustibles (Cáceres, 2008; Hernández et al., 2009). Los fructanos constituyen los principales carbohidratos de reserva en algunas familias del reino vegetal; son polímeros de fructosa de cadena lineal unidas por enlaces glucosídicos $\beta(2,1)$ y $\beta(2,6)$, sólo contienen un residuo de glucosa en el extremo reductor de la molécula y pueden alcanzar grados de polimerización hasta de 200 unidades de fructosa, lo cual depende de la fuente botánica así como de las condiciones agronómicas del cultivo y la edad de la planta (López et al., 2003). Entre las principales fuentes potenciales de fructanas destacan los tubérculos de la planta de alcachofa de Jerusalén (Helianthus tuberosus), las raíces de la planta de achicoria (Chicory intybus), los tubérculos de la planta de dalia (Dahlia variabilis) y las cabezas o piñas de las plantas del género Agave como el agave tequilero (Agave tequilana Weber Azul), el cual se cultiva de manera intensiva en nuestro país en una superficie cercana a las 100 mil hectáreas (López et al., 2003).

El Agave tequilana Weber Azul es una planta que requiere de 7 a 10 años para su desarrollo y sus ciclos de cultivo se ven afectados por las condiciones ambientales, manejo y diferencias genéticas de las plantaciones. La planta del agave tequilero está conformada por dos partes principales que son: la cabeza o piña y las hojas (Fig. 1). La cabeza representa la parte comercial de la planta y se utiliza como materia prima en el proceso de elaboración de "tequila", principal bebido alcohólica mexicana de consumo mundial. El peso promedio de la cabeza del agave va de 30 a $70 \mathrm{~kg}$., aunque se han obtenido cultivos cuyas cabezas han llegado a pesar entre 80 y $120 \mathrm{~kg}$., y dentro de estos, cabezas de hasta $150 \mathrm{~kg}$ y con un contenido de azúcares reductores totales que oscila entre 16 a $28 \%$ en peso fresco. Por su parte, las hojas o pencas constituyen los residuos agrícolas del cultivo, representan del 45 al $50 \%$ del peso total de la planta, miden de $90-120 \mathrm{~cm}$ de longitud y de 8 a $12 \mathrm{~cm}$ de ancho y su contenido de azúcares reductores totales oscila entre 3.3 a $16.1 \%$ en peso fresco, lo cual depende de la edad de la planta, las condiciones agronómicas del cultivo, y de la proximidad de las hojas hacia la cabeza o piña de la planta (Iñiguez et al., 2001). 


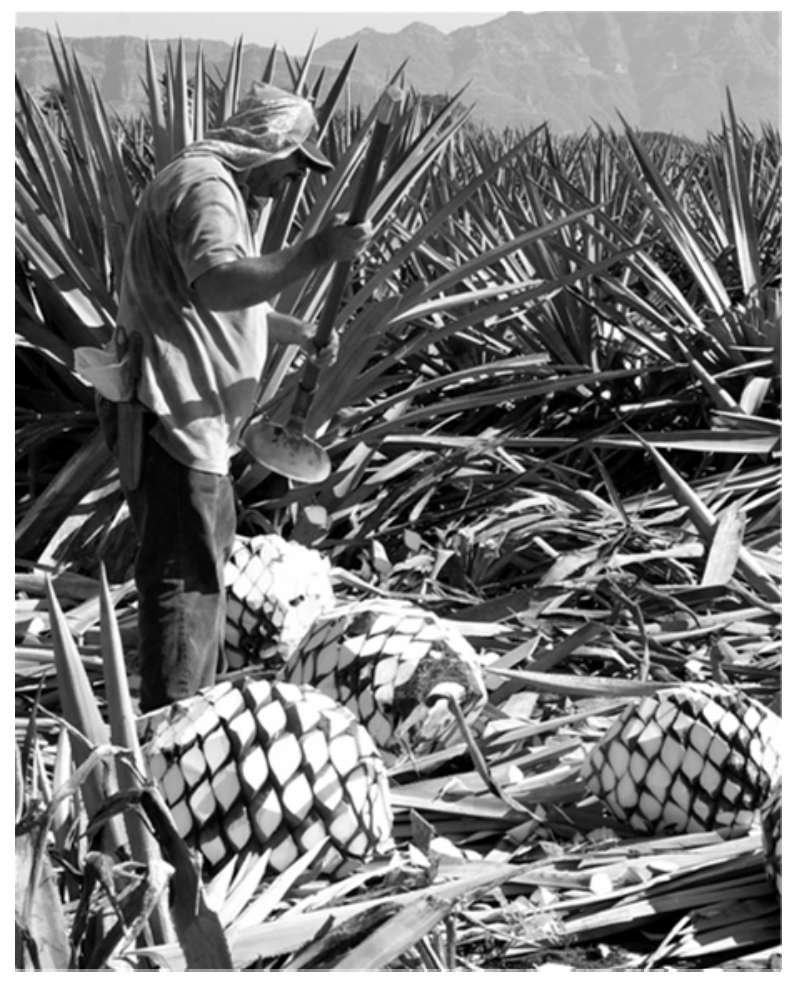

Fig. 1: Cosecha del Agave tequilana Weber Azul, plantas completas, hojas y cabeza o piña

Se han aplicado tres diferentes estrategias para la obtención de bioetanol por fermentación de los fructanos. La primera consiste en la fermentación directa de estos polímeros mediante el uso de microorganismos productores de enzimas inulinasas tales como Kluyveromyces fragilis (Rosa et al, 1986), Kluiveromyces marxianus (Guiraud et al. 1982) y Saccharomyces rosei (Margaritis et al., 1983). La segunda consiste en hidrolizar previamente de los fructanos mediante el empleo de ácidos minerales y su posterior fermentación a etanol por microorganismos que no producen inulinasas como Saccharomyces cereviciae (Díaz et al., 2008; Hernández et al., 2009) y Zymomonas mobilis (Toran et al., 1985). La tercera consiste en realizar previamente la sacarificación de los fructanos mediante un microorganismo productor de inulinasas (Aspergillus niger) y posteriormente fermentar los azúcares con un microorganismo productor de etanol como lo es la levadura Saccharomyces cerevisiae (Nakamura et al., 1996).

Anualmente la industria tequilera demanda aproximadamente un millón de toneladas de piñas de agave, actividad que genera una cantidad similar de hojas que constituyen los residuos agrícolas del cultivo y que no son utilizadas en la actualidad (Iñiguez et al., 2001). Aunado a ello, hoy en día existe una sobreproducción de agave tequilero que ocasiona pérdidas anuales cercanas a las 100,000 toneladas (Narváez y Sánchez 2009). Por lo anterior, la finalidad de este trabajo consistió en utilizar los residuos agrícolas del cultivo del agave tequilero (Agave tequilana Weber Azul), como materia prima fuente de azúcares fermentables para la producción de bioetanol, mediante el empleo de dos diferentes microorganismos etanolgénicos; la levadura Saccharomyces cerevisiae y la bacteria Zymomona mobilis y comparar los resultados obtenidos.

\section{MATERIALES Y MÉTODOS}

Recolección, acondicionamiento y análisis de las hojas del agave

En un cultivo de Agave tequilana Weber Azul de ocho años de edad, localizado en el municipio de Venustiano Carranza, Mich., veinte plantas de agave fueron seleccionadas al azar, al momento de efectuarse la cosecha. Las hojas fueron separadas y cortadas por su mitad longitudinal, obteniendo así tres fracciones: cabeza o piña, bases y puntas de hojas; las bases corresponden a la porción de la hoja que va unida a la cabeza o piña de la planta. Se determinó el peso de cada fracción, así como su contenido de humedad (AOAC, 1995) y azúcares reductores totales (Miller, 1959). 


\section{Extracción de los fructanos}

Las bases de las hojas del agave fueron lavadas a chorro de agua y después fueron cocinadas en autoclave a $100^{\circ} \mathrm{C}$ durante 4 horas, a fin de hidrolizar los fructanos y facilitar la extracción del jugo. Enseguida las bases de las hojas fueron prensadas en un trapiche para obtener el jugo que después fue filtrado a través de papel filtro y posteriormente concentrado a $25 \%$ de ART en un evaporador rotatorio y a una temperatura de $70^{\circ} \mathrm{C}$.

\section{Microorganismos empleados}

Se utilizó una cepa de la levadura Saccharomyces cerevisiae (CDBB-L-331) y una cepa de la bacteria Zymomona mobilis (CDBB-B-603), las cuales fueron obtenidas de la Colección Nacional de Cepas Microbianas y Cultivos Celulares del CINESTAV-IPN México. Ambos microorganismos fueron resembrados mensualmente; la levadura se resembró en placas de agar YM cuya formulación es: glucosa $10 \mathrm{~g} / \mathrm{L}$, extracto de levadura $3 \mathrm{~g} / \mathrm{L}$, extracto de malta $3 \mathrm{~g} / \mathrm{L}$, peptona $5 \mathrm{~g} / \mathrm{L}$; agar $20 \mathrm{~g} / \mathrm{L}$ y agua destilada $1000 \mathrm{~mL}$; mientras que la bacteria se resembró en placas con medio YPG cuya formulación es: glucosa $20 \mathrm{~g} / \mathrm{L}$, peptona $10 \mathrm{~g} / \mathrm{L}$, extracto de levadura $3 \mathrm{~g} / \mathrm{L}$ y agua destilada $1000 \mathrm{~mL}$. El pH de los medios de cultivo se ajustó a 5 con $\mathrm{HCl} 0.1 \mathrm{M}$ y después de la resiembra, los medios se incubaron a $30^{\circ} \mathrm{C} / 24 \mathrm{hrs}$ y posteriormente se almacenaron en refrigeración a $5^{\circ} \mathrm{C}$.

\section{Preparación del preinoculo}

En dos matraces Erlenmeyer se adicionaron $500 \mathrm{~mL}$ de extracto de agave con $14 \%$ de ART, $1.5 \mathrm{~g}$ de extracto de levadura, $1.5 \mathrm{~g}$ de extracto de malta y $2.5 \mathrm{~g}$ de peptona. El pH del medio fue ajustado a 5 con $\mathrm{HCl} 0.1 \mathrm{M}$. Los medios de cultivo fueron esterilizados en autoclave a $121^{\circ} \mathrm{C} / 15 \mathrm{~min}$. Al matraz donde se propagará la bacteria $Z$. mobilis se le adicionó también $0.1 \mathrm{~g} / \mathrm{l}$ de ciclohexamida. Cada matraz fue inoculado con dos asadas del microorganismo correspondiente y posteriormente incubados a $30^{\circ} \mathrm{C} / 24 \mathrm{hrs}$. Al término de la incubación se determinó la concentración de microorganismos por el método de vaciado en placa. Se repitió el procedimiento anterior incrementando el número de asadas de cada microorganismo, hasta alcanzar una concentración de $2 \times 10^{6} \mathrm{UFC} / \mathrm{mL}$.

\section{Preparación del medio de fermentación}

Se prepararon 10 litros de jugo de agave con 10,15, 20, 25\% de ART. A cada concentración se le adicionó $1 \mathrm{~g} / \mathrm{L}$ de $\left(\mathrm{NH}_{4}\right)_{2} \mathrm{SO}_{4}$ y su pH se ajustó a 5.0 con $\mathrm{HCl} 0.1 \mathrm{M}$. Posteriormente se prepararon dos series de matraces Erlenmeyer de $250 \mathrm{ml}$, en los que se adicionaron $150 \mathrm{~mL}$ de jugo de agave a las distintas concentraciones. Los matraces se taparon con algodón y se esterilizaron en autoclave a $121^{\circ} \mathrm{C} / 15 \mathrm{~min}$. Posteriormente una serie de matraces fue inoculada con la levadura $S$. cerevisiae y la otra con la bacteria $Z$. mobilis; a esta ultima también se le adicionó $0.1 \mathrm{~g} / \mathrm{l}$ de ciclohexamida. La cantidad de inoculo adicionado en ambos casos fue de $5 \% \mathrm{v} / \mathrm{v}$. Después de la inoculación, los matraces fueron incubados a $30^{\circ} \mathrm{C}$ durante 24 horas en la obscuridad y con agitación constante a $100 \mathrm{rpm}$ en un agitador rotatorio. Al término de la incubación, en el caldo de fermentación se determinó la concentración de microorganismos por el método de vaciado en placa y después de filtrar el caldo fermentado a través de una membrana de acetato de celulosa de 0.45 micras de diámetro, también se determinó su contenido de ART (Miller, 1959), etanol (ebulloscopia) y $\mathrm{pH}$. El mismo procedimiento fue aplicado para mayores tiempos de fermentación $(48,72,96$, y 120 horas) y todas las determinaciones se hicieron por triplicado.

\section{Métodos analíticos}

El contenido de humedad se evaluó de acuerdo al método 14.003 (AOAC. 1997). El contenido de sólidos solubles ( ${ }^{\circ}$ Brix) se determinó mediante un refractómetro PCE 032 (PCE Ibérica S.L.). El contenido de azucares reductores directos (ARD) y azúcares reductores totales (ART) se determinó por el método de Miller (1959). La concentración de biomasa celular se determinó por el método de vaciado en placa. La concentración de etanol en las muestras de mosto fermentado 
se determinó mediante un ebullómetro Dujardin-Salleron Modelo 359, equipado con regulación electrónica de calefacción $110 \mathrm{~V}$ - CE (Laboratories Dujardin-Salleron, Francia), los valores de productividad de etanol se calcularon dividiendo el contenido de alcohol por el tiempo de fermentación, teniendo en cuenta una densidad $0.789 \mathrm{~g} / \mathrm{mL}$ de etanol a $20^{\circ} \mathrm{C}$. El pH del medio se determinó con un potenciómetro (Condutronic pH20, México).

\section{Análisis estadístico}

El diseño experimental se basó en un arreglo factorial con distribución al azar. Se probaron dos diferentes microorganismos etanolgénicos (S. cereviciae y Z. mobilis), la fermentación se llevó a cabo a cuatro diferentes concentraciones de azúcares $(10,15,20,25 \%$ de ART) y a 5 diferentes tiempos de fermentación ( $24,48,72,96$, y 120 horas). La combinación de estas variables produjo 40 arreglos distintos y se hicieron tres replicas de cada uno de ellos. Como variables de respuesta se midió la concentración de etanol producido, así como el contenido de ART residuales y la concentración de microorganismos. Se realizó un análisis de ANOVA para cada microorganismo con el software Statgraphics plus versión 5.1.Copyrigth 1994-2001 por Statical Graphics Corp.

\section{RESULTADOS Y DISCUSIÓN}

La cabeza o piña del agave tequilero constituye el $51.45 \pm 2.85 \%$ del peso total de la planta; el restante $48.55 \%$ está comprendido por las hojas o pencas (puntas de hojas $16.40 \pm 1.25 \%$, bases de hojas $32.15 \pm 1.85 \%$ ), las cuales representan los residuos agrícolas del cultivo. En la Tabla 1 se muetran valores promedio de tres determinaciones \pm desviación estándar. Las letras diferentes entre columnas del mismo renglón indican diferencias estadísticas significativas $(p<0.05)$.

El mayor contenido de ART se localiza en la piña, razón por la que esta fracción constituye la parte comercial de la planta y se utiliza como materia prima fuente de azúcares fermentables en el proceso de elaboración de tequila. Una importante cantidad de ART está contenida en las bases de las hojas del agave $(52.45 \pm 2.45 \%)$ y a pesar de la alta contribución de ésta fracción en el peso total de la planta $(32.15 \pm 1.85 \%)$ y a los grandes volúmenes de producción (aproximadamente un millón de toneladas anuales) (Valenzuela, 2000), actualmente no se aprovechan.

Tabla 1: Análisis químico proximal de las diferentes fracciones del Agave tequilana Weber Azul

\begin{tabular}{|c|c|c|c|}
\hline Parámetro & $\mathrm{Fra}$ & $d e$ & $\mathrm{plant} a$ \\
\hline & Puntas de hojas & Bases de hojas & Cabeza o piña \\
\hline Proporción (\% \%ase Húmeda) & $16.40 \pm 1.25^{a}$ & $32.15 \pm 1.85^{\mathrm{b}}$ & $51.45 \pm 2.85^{\mathrm{c}}$ \\
\hline Humedad (\% $\%_{\text {Base Húmeda) }}$ & $80.25 \pm 1.45^{d}$ & $78.65 \pm 1.55^{d}$ & $72.50 \pm 1.25^{\mathrm{e}}$ \\
\hline ART (\% \%ase seca) & $25.75 \pm 2.35^{f}$ & $52.45 \pm 2.45^{\mathrm{g}}$ & $80.35 \pm 2.25^{\mathrm{h}}$ \\
\hline
\end{tabular}

\section{Consumo de azúcares}

La evolución del proceso de fermentación de los azúcares extraídos de las bases de las hojas del Agave tequilana Weber Azul fue diferente para cada microorganismo (Fig. 2). El máximo consumo de ART se alcanzó dentro de las primeras 72 horas del proceso de fermentación y fue mayor cuando la fermentación se llevó a cabo con $Z$. mobilis que con $S$. cerevisiae. Altas concentraciones de ART inhiben el crecimiento de ambos microorganismos, especialmente de $S$. cerevisiae donde la inhibición fue manifiesta a concentraciones de ART mayores de $15 \%$. Scopes y Griffiths, (1986) señalan que $Z$. mobilis tolera mayores concentraciones de azúcares debido a que las enzimas de su ruta metabólica Enter-Doudoroff no se inhiben por las altas concentraciones de azúcares, como consecuencia de una rápida conversión de glucosa a etanol en este microorganismo. Por el contrario, se ha demostrado que S.cereviciae es poco osmotolerante y fermenta mejor a bajas concentraciones de azúcares, que en este caso fue a una concentración de ART menor al 15\%, resultado que concuerda con lo reportado por Alfenore et al. (2002). 



Fig. 2: Consumo de azúcares por Zymomonas mobilis (A) y Saccaromyces cerevisiae (B) en función del tiempo de fermentación y a diferentes concentraciones de azúcares reductores totales, $\mathrm{pH}=5.0$ y $\mathrm{T}=30^{\circ} \mathrm{C}$. En la figura: es $10 \%$ ART; $\square$ es $15 \%$ ART; $\Delta$ es $20 \%$ ART y $x$ es $25 \%$ ART.

La alta concentración de azúcares residuales en el medio muestra que la fermentación fue incompleta, especialmente cuando ésta fue llevada a cabo con la levadura S. cerevisiae, lo cual indica una posible inhibición del crecimiento celular que ha sido atribuible a la falta de elementos esenciales como nitrógeno y fósforo (Bai et al., 2004), aminoácidos y vitaminas (Winter et al., 1989; Taherzadeh et al., 1996). Se ha reportado también que el jugo de agave contiene sustancias conocidas como saponinas, las cuales inhiben el crecimiento de algunos microorganismos (Montaño et al., 2007). Por otra parte, durante el tratamiento térmico aplicado a las bases de las hojas del agave para extraer, hidrolizar, concentrar y esterilizar el jugo, se degradan vitaminas termolábiles y nitrógeno asimilable a causa de las reacciones de Maillard, en las cuales se generen compuestos de furfural que han demostrado ser tóxicos para las levaduras (Mancilla y López 2002).

\section{Producción de bioetanol}

En ambos casos la máxima producción de bioetanol se obtuvo dentro de las primeras 72 horas de iniciado el proceso de fermentación, pues no hubo diferencias estadísticas significativas $(p>0.05)$ en la producción de bioetanol a mayores tiempos de fermentación. Cuando la fermentación se lleva a cabo con la bacteria Z mobilis, la máxima producción de bioetanol $(8.2 \pm 0.3 \% \mathrm{v} / \mathrm{v})$ se obtuvo a una concentración del $20 \%$ de ART, mientras que cuando la fermentación es llevada a cabo con la levadura Saccharomyces cerevisiae, la máxima producción de bioetanol $(5.1 \pm 0.25 \% \mathrm{v} / \mathrm{v})$ se obtuvo en un tiempo de a una concentración de $15 \%$ de ART (Fig. 3).

A bajas concentraciones de azucares reductores totales $(10 \%$ de ART), la cinética de fermentación y por la tanto la producción de bioetanol es similar entre ambos microorganismos, pero a mayores concentraciones de azúcares (15-25\%), la utilización de azúcares y por lo tanto, la producción de bioetanol es mayor cuando la fermentación se lleva a cabo con la bacteria $Z$. mobilis, lo que indica que este microorganismo tolera mayores concentraciones de azúcares y de bioetanol en el medio, lo cual se atribuye a que dicho microorganismo presenta tanto un sistema de difusión facilitada que le permite un rápido equilibrio entre las concentraciones celulares internas y externas de estos compuestos (Struch et al., 1991; Nowak 2001), así como un sistema enzimático más resistente a altas concentraciones de bioetanol, lo que ha permitido alcanzar concentraciones de bioetanol hasta de un 15\% p/v (Algar y Scopes, 1985). Otros estudios indican que la mayor tolerancia y producción de bioetanol por $Z$. mobilis se debe a la composición de ácidos grasos que presenta la membrana celular de este microorganismo, dichos ácidos grasos contrarrestan los efectos adversos del bioetanol sobre la membrana celular (Buchholz et al., 1987). Por otro lado, la menor producción de bioetanol por la levadura S.cereviciae se atribuye al efecto tóxico que tiene el alcohol sobre la membrana celular de este microorganismo (Chi \& Arneborg, 1999). 

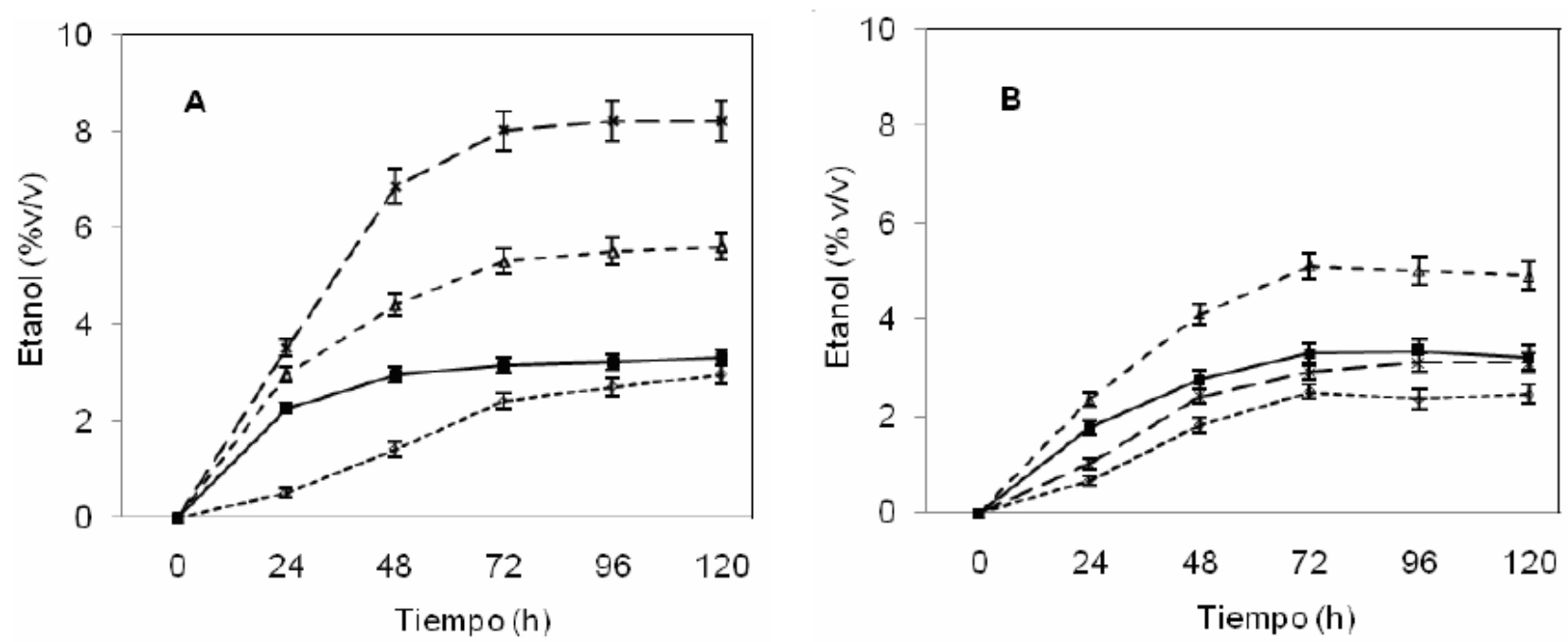

Fig. 3: Producción de etanol por Zymomonas mobilis (A) y por Saccharomyces cerevisiae (B) en función del tiempo de fermentación y a diferentes concentraciones de azúcares reductores totales, $\mathrm{pH}=5.0$ y $\mathrm{T}=30^{\circ} \mathrm{C}$. En la figura: es $10 \%$ ART; $\square$ es $15 \%$ ART; $\Delta$ es $20 \%$ ART y x es $25 \%$ ART.

\section{Crecimiento celular}

Contrario a lo sucedido con el consumo de azúcares reductores y con la producción de bioetanol, el crecimiento celular de $S$. cerevisiae fue mayor que el de $Z$. mobilis; en ambos casos el máximo crecimiento celular se alcanzó en un tiempo de 72 horas (Fig. 4) y la máxima concentración celular de Z. mobilis fue de $6.8 \pm 0.54 \times 10^{7} \mathrm{UFC} / \mathrm{ml}$ y se obtuvo a una concentración de ART de $20 \%$, mientras que la máxima concentración celular de S.cerevisiae fue de $3.52 \pm 0.24 \times 10^{8} \mathrm{UFC} / \mathrm{ml}$, y se obtuvo a una concentración de $15 \%$ de ART. Se ha comprobado que en condiciones de anaerobiosis, el menor crecimiento celular de la bacteria Zymomonas mobilis se debe a que este microorganismo sólo convierte el $2 \%$ de la fuente de carbono en biomasa y fermenta el $98 \%$ restante (Rogers et al., 1986).
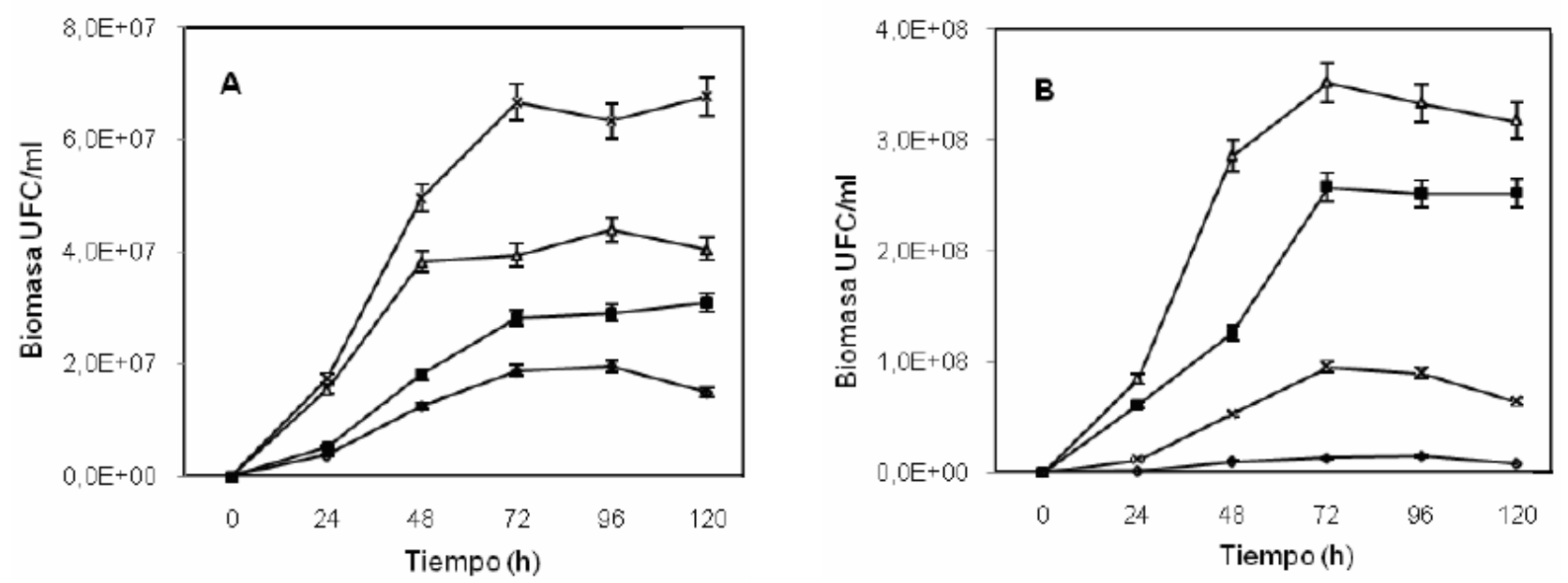

Figura 4: Crecimiento celular de Zymomonas mobilis (A) y de Saccharomyces cerevisiae (B) en función del tiempo de fermentación a diferentes concentraciones de azúcares reductores totales, $\mathrm{pH}=5.0$ y $\mathrm{T}=30^{\circ} \mathrm{C}$. En la figura: es $10 \%$ ART; $\square$ es $15 \%$ ART; $\Delta$ es $20 \%$ ART y x es $25 \%$ ART.

En la tabla 2 se muestra el resumen de los parámetros cinéticos obtenidos bajo las condiciones óptimas de fermentación para ambos microorganismos. En la Tabla, los valores representan el promedio de tres determinaciones \pm desviación estándar. Letras diferentes entre columnas del mismo renglón indican diferencias estadísticas significativas $(p<0.05)$. 1: Gramos de etanol 
producido / gramo de ART consumidos; 2: Gramos de etanol producido x 100 / 0.511 x gramo de ART consumidos; 3: Gramos de etanol producido / tiempo óptimo de la fermentación.

Se puede observar que la bacteria $Z$. mobilis tuvo un mayor consumo de azucares $(139 \pm 3.5 \mathrm{~g} / \mathrm{L})$, así como una mayor producción de etanol $(80 \pm 3.5 \mathrm{~g} / \mathrm{L})$ que la S.cerevisiae. También se observa que $Z$. mobilis tuvo mayor rendimiento en la producción de etanol $(0.58 \pm 0.02$ gramos de etanol producido / gramo de ART consumido), así como mayor eficiencia de la conversión de azúcar a etanol (112.67 \pm 2.9 gramos de etanol obtenido / gramo de azúcar metabolizado) y una mayor productividad volumé-trica $(1.1 \pm 0.01$ gramos de etanol producido $/ \mathrm{L} \times \mathrm{h}$ ).

Tabla 2: Parámetros cinéticos óptimos de la fermentación de los azúcares del Agave tequilana Weber Azul por Zymomonas mobilis y por Saccharomyces cerevisiae a $\mathrm{pH}=5$ y $\mathrm{T}=30^{\circ} \mathrm{C}$

\begin{tabular}{|c|c|c|}
\hline Parámetro & Zymomonas mobilis & Saccharomyces cerevisiae \\
\hline Concentración inicial de ART (g/L) & $200 \pm 3.1^{\mathrm{a}}$ & $150 \pm 2.3^{b}$ \\
\hline Tiempo de fermentación óptimo (h) & $72^{\mathrm{a}}$ & $72^{\mathrm{a}}$ \\
\hline Concentración final de ART (g/L) & $61 \pm 3.1^{\mathrm{a}}$ & $48 \pm 2.9^{b}$ \\
\hline Consumo de ART (g/L) & $139 \pm 3.5^{\mathrm{a}}$ & $102 \pm 3.8^{b}$ \\
\hline Crecimiento celular (UFC/mL) & $6.7 \pm 0.5 \times 10^{7 a}$ & $3.5 \pm 0.3 \times 10^{8 b}$ \\
\hline Producción de bioetanol (g/L) & $80 \pm 3.5^{\mathrm{a}}$ & $51 \pm 2.8^{\mathrm{b}}$ \\
\hline Rendimiento de bioetanol $^{1}$ & $0.58 \pm 0.02^{\mathrm{a}}$ & $0.50 \pm 0.01^{b}$ \\
\hline Eficiencia de conversión ${ }^{2}$ & $112.6 \pm 2.9^{a}$ & $98.1 \pm 1.8^{\mathrm{b}}$ \\
\hline Productividad volumétrica ${ }^{3}$ & $1.1 \pm 0.01^{\mathrm{a}}$ & $0.71 \pm 0.01^{\mathrm{b}}$ \\
\hline
\end{tabular}

Un estudio similar fue realizado por Cáceres et al., (2008), quienes al fermentar el jugo de las hojas del henequén (Agave fourcroydes Lem.) mediante la bacteria Z. mobilis, obtuvieron una producción máxima de etanol de $5.22 \pm 1.09 \% \mathrm{v} / \mathrm{v}$, inferior a la obtenida en nuestro estudio. Resultados similares a los obtenidos en nuestro estudio fueron obtenidos por Canseco et al., (2008), quienes al emplear la bacteria Z. mobilis para fermentar los azúcares presentes en los residuos agroindustriales del cultivo del papayo (Caricae papaya) obtuvieron una producción máxima de etanol de $8.9 \% \mathrm{v} / \mathrm{v}$. Por su parte, Kannan, et al., (1998) encontraron que Z. mobilis presenta ventajas sobre Saccharomyces cerevisiae en la producción de etanol, tanto en cultivo por lote como en cultivo continuo; dichas ventajas son: tolera mayores concentraciones tanto de sustrato como de etanol en el medio; presenta mayor rendimiento de etanol producido por mol de glucosa fermentada; genera un bajo nivel de biomasa; además, $Z$. mobilis es un microorganismo tanto homo como heterofermentador.

Buscando optimizar las condiciones de fermentación en el proceso de producción de mezcal a partir de los fructanos contenidos en la cabeza del Agave salmiana, De León et al., (2008) demostraron que las condiciones del proceso fermentativo afectan la calidad del mezcal, así como la cantidad de etanol producido. Obtuvieron la mayor producción de etanol $(37.7 \mathrm{~g} / \mathrm{L})$ a una temperatura de $28^{\circ} \mathrm{C}$ y una concentración inicial de azúcares de $105 \mathrm{~g} / \mathrm{L}$, sin embargo, la máxima productividad del proceso la obtuvieron a $34.6^{\circ} \mathrm{C}$ y $90 \mathrm{~g} / \mathrm{L}$ de azúcares, mientras que el máximo rendimiento de producto y la mejor calidad del mezcal la obtuvieron cuando la fermentación la llevaron a cabo a una temperatura de $28^{\circ} \mathrm{C}$ y a una concentración inicial de azúcares de $77 \mathrm{~g} / \mathrm{L}$. Concluyen que la mayor producción de etanol y la mayor velocidad de crecimiento del microorganismo no son compatibles, debido a que para obtener una mayor producción de etanol se requiere de altas concentraciones de sustrato, lo que a su vez inhibe la velocidad de crecimiento del microorganismo.

Los resultados obtenidos en este estudio como son: producción de etanol, rendimiento, consumo y asimilación de altas concentraciones de de azúcar y el menor crecimiento celular de la bacteria $Z$. mobilis con respecto a la S.cerevisiae, coinciden con los obtenidos por otros investigadores (Kannan, et al., 1998 y Nowak, 2001). 
El empleo del Agave tequilana Weber Azúl como materia prima para la producción de bioetanol, presenta importantes ventajas sobre otras metodologías como son: dado que esta planta no es utilizada en la alimentación humana ni animal, su utilización en la producción de bioetanol no atenta contra la seguridad alimentaria de la población. Por otro lado, el cultivo del agave demanda menor cantidad de agua y fertilizantes, es capaz de crecer en suelos pobres y no aptos para los cultivos alimentarios y resiste temperaturas extremas. Otra ventaja más lo constituyen los altos rendimientos del cultivo de esta planta, cuyo rendimiento promedio nacional actualmente es de 160 ton/ha, que repartidas en los diez años que dura el ciclo del cultivo, arroja un rendimiento promedio de 16 ton/ha $x$ año, y un volumen similar de hojas o pencas que actualmente no son utilizadas. Este rendimiento del cultivo del agave se encuentra muy por arriba de los rendimientos que se obtienen de otros cultivos como el maíz por ejemplo, principal materia prima empleada en la producción de bioetanol en los Estados Unidos de América (Wheals et al., 1999) y cuyo rendimiento nacional de su cultivo es de sólo 3 ton/ha (Valenzuela, 2000). Finalmente, la utilización de las hojas del Agave Tequilana Weber Azul como materia prima para la producción industrial de bioetanol, no requiere de fuertes inversiones tecnológicas debido a que este bioproceso es simple y su tecnología es similar a la que se utiliza actualmente en el proceso de producción de tequila.

\section{CONCLUSIONES}

Debido a su alto contenido de azúcares reductores totales ( $52.45 \pm 2.45 \%$ en peso seco) y a los elevados volúmenes de producción (aproximadamente un millón de toneladas anuales), las hojas o pencas del Agave tequilana Weber Azul constituyen una prometedora materia prima para la producción industrial de bioetanol.

En el proceso de producción de bioetanol por fermentación de las fructanas del agave, la bacteria Zimomonas mobilis presentó ciertas ventajas sobre la levadura Saccharomyces cerevisiae como son: mayor rendimiento en la producción de etanol, mayor eficiencia de conversión de azúcares en etanol, mayor productividad volumétrica y una menor inhibición a altas concentraciones de etanol y de azúcares en el medio. Es por ello que, dadas las ventajas mencionadas, la bacteria Zymomonas mobilis presenta un gran potencial para la producción industrial de etanol por fermentación.

La utilización de las hojas o pencas del Agave tequilana Weber Azul para la producción de bioetanol es una alternativa viable y sustentable que no pone en riesgo la seguridad alimentaria de la población, debido a que éstos residuos agrícolas no forman parte de la alimentación humana ni animal, y su utilización en este proceso contribuye al aprovechamiento integral del cultivo

\section{AGRADECIMIENTOS}

Agradecemos al Instituto Politécnico Nacional que a través de la Secretaría de Investigación y Posgrado, nos haya brindado el apoyo económico para la realización de este proyecto con clave SIP: 20090367.

\section{REFERENCIAS}

AOAC. Official Methods of Analysis Fourteenth edition. Association of Official Analytical Chemists. Pags: 131, 211 y 858. Washington, U.S.A. (1997).

Alfenore, S., L. Benbadis, C. Bideux y G. Goma, Improving ethanol production and viability of Sacharomyces cerevisiae by a vitamin feeding strategy during fed batch processs. Appl Microbial Biotechnol., 60, 67-72 (2002).

Algar, E. y R. Scopes, Studies on cell-free metabolism: ethanol production by extracts of Zymomonas mobilis. J. Biotechnol., 2, 275-287 (1985).

Avinash, K., Biofuels applications as fuels for internal combustion engines. Progress in Energy and Combustion Science, 33 (3), 233-271 (2007). 
Bai, F., L. Chen, Z. Zhang, W. Anderson y Y. Moo, Continuous ethanol production and eva-luation of yeasts cell lysis and viability loss under very high gravity medium conditions, J. Biotechnol., 110:287-293 (2004).

Buchholz, S., M. Dooley y D. Eveleigh, Zymomonas: an alcoholic enigma. Trends Biotechnol., 5:199-204 (1987).

Cáceres, F., P. Lappe, S. Larque, M. Magdub y P. Barahona, Ethanol production from henequen (Agave fourcroydes Lem.) juice and molasses by a mixture of two yeasts. Bioresource Technology, 99, 9036-9039 (2008).

Canseco, M., B. Couder, Y. Pérez, P. Álvarez y T. Saldaña. Producción de etanol a partir de desechos agroindustriales. Cuerpo académico de Investigación y Desarrollo Agroindustrial. Universidad politécnica de Chiapas. XIII Congreso Nacional de Biotecnología y Bioingeniería, (2008).

Chi, Z., y N. Arneborg, Relationship between lipid composition, frequency of ethanol-induced respiratory deficient mutants, and ethanol tolerance in Sachharomyces cereviciae mutants, and ethanol tolerance in Saccharomyce cerevisiae. J. Appl. Microbiol., 86, 1047-1052 (1999).

De León, R., P. Escalante, A. Barba, H. Blaschek, Optimization of fermentation conditions for the production of the mescal from Agave salmiana using response surface methodology. Chemical Engineering and Processing 47, 76-82 (2008).

Diaz, M., L. Marie, E. Estarrón y P. Strehaiano, Fermentative capability and aroma com-pound production by yeast strains isolated from Agave tequilana Weber juice. Enzyme and Microbial Technology, 42, 608-616 (2008).

Guiraud, J., J. Caillaud y P. Galzy, Optimization of alcohol production from Jerusalem artichokes. Eur. J. Appl. Microbiol. Biotechnol., 14, 81-85 (1982).

Hernández, S., M. Villa, J. Veloz, K. Rivera, R. González, M. Plasencia y E. Trejo. Comparative hydrolysis and fermentation of sugarcane and agave bagasse. Bioresource Technology, 100, 1238-1245 (2009).

Idarraga, G., J. Ramos, V. Zúñiga y T. Sahin, Pulp and paper from agave waste from tequila production. J. Agric. Food Chem., 47, 4450-4455 (1999).

Iñiguez, G., R. Díaz, R. Sanjuan, J. Anzaldo y R. Rowell, Utilization of by-products from the tequila industry. Part 2: potential value of Agave tequilana Weber azul leaves. Bioresource Technology, 77, 101-108 (2001).

John, M., Seven steps to curb global warming. Energy Policy. 355(8), 4247-4259 (2007).

Kannan, T., G. Sangiliyandi y P. Gunasekaran, Improved ethanol production from sucrose by a mutant of Zymomonas mobilis lacking sucrases in immobilized cell fermentation. Enzyme Microbial Technology, 22(3),179-184 (1998).

López, G., M. Mancilla y D. Mendoza, Molecular structures of fructans from Agave tequilana Weber azul. J. Agric. Food Chem., 51,7835-7840 (2003).

Mancilla, M. y M. López, Generation of Maillard compounds from inulin during thermal proce-ssing of Agave tequilana blue variety. J. Agric. Food Chem., 50, 806-812 (2002)

Margaritis, A., F. Merchant y I. Veliky, Fermentation of polyfructans to ethanol by Saccharomyces rosei. Biotechnol. Lett., 5, 271-276 (1983). 
Miller, G., Use of dinitrosalicylic acid reagent for determination of reducing sugar. Anal. Chem., 31, 426-428 (1959).

Montaño, D., M. Line, E. Espinosa y P. Strehaiano, Fermentative capability and aroma com-pound production by yeast strains isolated from Agave tequilana Weber juice. Enzyme and Microbial Technol., 42, 608-616 (2007).

Nakamura, T., Y. Ogata, A. Shitara y K. Ohta, Etanol production from Jerusalem artichoke tubers by Aspergillus niger and Saccharomyces cerevisiae. Journal of Fermentation and Bioengineering, 81(6), 564-566 (1996).

Narvaez, Z.J. y T.F. Sanchez, Agaves as a raw material, recent technologies and applications. Recent Patents on Biotechnology, 3 (3), 1-7 (2009).

Nowak, J., Comparison of polish industrial distillery yeast with ethanol producing bacteria Zymomonas mobilis. Food Science and Technol., 4, 2-6 (2001).

Prasad, S., A. Singh y $\mathrm{H}$. Joshi, Ethanol as an alternative fuel from agricultural, industrial and urban residues. Resources, Conservation and Recycling, 50, 1-39 (2007).

Rogers, P., A. Strzelecki y A. Goodman, Commercial potential of Zymomonas process for ethanol production. Found. Biotechnol. Industr. Ferm. Res., 4, 63-79 (1986).

Rosa, M., A. Vieira y M.L. Bartolomeu, Production of high concentration of ethanol from mash, juice and pulp of Jerusalem artichoke tubers by Kluyveromyces fragilis. Enzyme Microbiol. Technol., 8, 673-676 (1986).

Sanchez, O. y C. Cardona, Trends in biotechnological production of fuel ethanol from diffe-rent feedstocks. Bioresource Technology, 99, 5270-5295 (2008).

Scopes, R. y S. Griffiths, Fermentation capabilities of Zymomonas mobilis glycolytic enzymes. Biotechnol. Lett., 8, 653-656 (1986).

Struch, T., B. Neuss y M. Bringer, Osmotic adjustment of Zymomonas mobilis to concentred glucose solution. Appl. Microbiol. Biotechnol., 23, 201-211 (1991).

Taherzadeh, M., G. Liden y C. Klasson, The effects of pantothenato deficience and acetate adition on anaerobic batch fermentation of glucose by Sacharomyces cerevisiae. Appl Microbiol Biotechnol., 46, 176-182 (1996).

Toran, D., V. Jain, J. Allais y J. Baratti, Effect of acid or enzymatic hydrolysis on ethanol production by Zymomonas mobilis growing on Jerusalem artichoke juice. Biotech. Lett., 7, 527-530 (1985).

Valenzuela, Z. A., El agave tequilero: su cultivo e industria. 10-35. Lítteris Editores 2a Edición. México, (2000).

Torney F, L. Moeller, A. Scarpa and K. Wang, Genetic engineering approaches to improve bioethanol production from maize. Current opinion in Biotechnology, 18 (3), 193-199 (2007).

Wheals, A., L. Basso, D. Alves y H. Amorim, Fuel ethanol after 25 years. TIBTECH, 17(12), 482487 (1999).

Winter, J., M. Loret y J. Uribelarrea, Inhibition and growth factor deficiencies in alcoholic fermentation by Saccharomyces cerevisiae. Curr. Microbiol., 18, 247-252 (1989). 
